\title{
INTEGRASI ILMU USHUL, FIQIH DAN TASAWWUF DALAM MEMBANGUN KARAKTER MUKMIN PADA PESERTA DIDIK
}

\author{
Baihaqi \\ IAIN Pontianak, Indonesia \\ imamulbaihaqi@ymail.com
}

\begin{abstract}
Character education is education that is highly expected to be an identity of Indonesian education. It is conveyed on every occasion such as seminars, symposiums, discussions, even Nawacita from the current President of Indonesia (Joko Widodo) that Indonesian education should be better. One way to achieve is that education should be character-based and use knowledge as a basic framework. The world of education also teaches religion as a curriculum content, which is oriented towards education. It aims to educate students in order to have moral virtue. However, its effort still has not found maximum results, because religionas a subject matter is still independent and cannot yet be synergized. Even the majority of those taught are only religious jurisprudence (Islamic law) which needs to be formulated with religious study material that discusses ushul from what will become a real practice so that religious practices and rituals do not become ambiguous. This should be done because the end of religious studies must give contributions to "What is done and practiced must be accepted logically for everyone practicing from the teachings of the religion it self".
\end{abstract}

Keywords: Usul, Fiqh, Tasawwuf, Character, Believer, and Learners.

\begin{abstract}
Abstrak: Pendidikan karakter adalah pendidikan yang sangat diharapkan menjadi jati diri pendidikan Indonesia pada kesempatan ini, di mana-mana disampaikan agar supaya pendidikan Indonesia semakin baik, melalui seminar, simposium, diskusi-diskusi, bahkan Nawacita dari Presiden RI saat ini (Joko Widodo) salah satunya menginginkan pendidikan mesti berbasis karakter, tentu ilmu pengetahuan sebagai bahan dari dunia pendidikan mesti menjadi kerangka mendasar. Dunia pendidikan yang juga mengajarkan ilmu agama sebagai muatan kurikulum, yang berorientasi kepada pendidikan, bertujuan untuk mewujudkan peserta didik agar supaya mempunyai akhlakul karimah, pada kesempatan ini masih belum menemukan hasil yang maksimal, disebabkan ilmu pengetahuan agama masih berdiri sendiri dan belum bisa bersenergi. Bahkan mayoritas yang diajarakan hanya pelajaran agama yang bercorak fiqih (hukum Islam), sebab itulah perlu diformulasikan bahan pelajaran agama yang membahas tentang ushul dari setiap sesuatu yang nantinya akan menjadi amalan yang nyata sehingga amalan dan ritual agama tidak menjadi ambigu, karena akhir dari pelajaran agama mesti memberikan konstribusi "Apa yang dilakukan dan diamalkan mesti diterima oleh akal bagi setiap pengamal dari ajaran agama itu sendiri".
\end{abstract}

Kata Kunci: Ushul, Fiqih, Tasawwuf, Karakter, Mukmin, dan Peserta Didik. 


\section{A. Pendahuluan}

Akhir-akhir ini, dunia pendidikan mulai ramai mewacanakan pendidikan karakter, meskipun sebenarnya pendidikan karekter itu tidak hal baru. ${ }^{115}$ Karakter yang dimaksud ialah bagaimana membuat peserta didik mempunyai keperibadian yang santun, berakhlak mulia, patuh dan taat kepada aturan.

Wacana dan program tersebut sesuai dengan apa yang disampaikan dalam nawacita dari program Presiden RI yang ketujuh yaitu Joko Widodo, di mana poin delapan menyatakan bahwa melakukan revolusi karakter bangsa melalui kebijakan penataan kembali kurikulum pendidikan nasional dengan mengedepankan aspek pendidikan kewarganegaraan, yang menempatkan secara profesional aspek pendidikan, seperti pengajaran sejarah pembentukan bangsa, nilai-nilai patriotisme dan cinta tanah air, semangat bela negara dan budi pekerti di dalam kurikulum pendidikan Indonesia. ${ }^{116}$ Kemudian untuk merealisasikan salah satu nawacita tersebut, para stekholder bangsa ini membuat program pembangunan karakter anak bangsa, sesuai dengan isi nawacita Presiden RI.

Terkait dengan hal tersebut, dunia pendidikan di Indonesia yang mempunyai "dua wajah". Pertama, pendidikan di bawah naungan Kementerian Pendidikan dan Kebudayaan. Kedua, pendidikan di bawah naungan Kementerian Agama yang sama-sama "getol" berupaya mewujudkan salah satu dari nawacita Presiden.

Dalam hal ini, penulis tidak ingin membahas terlalu jauh dari kedua kementerian yang sama-sama juga mengurus dunia pendidikan. Pada kesempatan kali ini, penulis hanya ingin menyampaikan bahwa pendidikan yang ada sekarang ini belum sepenuhnya berhasil membentuk karakter anak bangsa yang diidamidamkan. Hal ini dilatarbelakangi dengan adanya beberapa kasus yang terjadi terkait kenakalan peserta didik semakin bertambah. Bahkan, akhir-akhir ini berita yang menghebohkan tentang seorang siswa SMA yang menganiaya gurunya di Kabupaten Sampang Jawa Timur yang berakhir dengan kematian gurunya. Peristiwa

115 Santo Budiono, Karekter Menentukan Masa Depan Bangsa, (Jakarta: PT. Gramedia, 2018), hlm. 409.

116 Inggried Dwi Wedhaswary, Nawacita Jokowi, https://nasional.kompos.com/read/ 2014/05 /0754454/, diakses pada 20 Maret 2018. 
tersebut telah 'mencoreng' dunia pendidikan yang menjadi garda terdepan dalam pembangunan karakter. ${ }^{117}$

Ada beberapa pendapat dari pengamatan pendidikan yang mengkritisi latar belakang terjadinya perilaku kekerasan di dunai pendidikan. Di antaranya ialah kurangnya jam pelajaran agama di sekolah, kurikulum agama kurang memberikan kesan tentang bagaimana menumbuhkembangkan karakter baik, bahkan sebagian besar pelajaran agama hanya masuk pada kategori fiqih, sedangkan ushul dari fiqih yang menjadi amalan nyata tidak pernah dijelaskan.

Analogi dari kritik tersebut dapat penulis contohkan dengan kasus yang sangat sederhana. Kenapa setiap orang Islam yang hendak menyambah kepada Allah SWT harus suci dari hadats besar dan dan hadats kecil? Sehingga terkadang penjelasannya menjadi ambigu atau tidak tasawwuf. Ada yang menyatakan bahwa karekter peserta didik belum bisa terwujud karena kurang terampilnya guru dalam memberikan sikap yang baik, 118 dan lain sebagainya yang diwacanakan dan didiskusikan oleh para ahli yang berkompeten dalam dunia pendidikan.

Menurut hemat penulis, apabila dikembalikan kepada pesan Tuhan dan NabiNya di dalam kitab suci al-Qur'an dan hadits, maka sebab utama dari rusaknya karakter peserta didik ialah hilangnya karakter mukmin dalam setiap pribadi anak bangsa. Inilah yang menjadi latar belakang dari tulisan ini. Mukmin adalah nama yang disebut dalam kitab al-Qur'an sebagai pribadi yang beruntung atau menang, diberi petunjuk, santun, menghargai persaudaraan dan hal-hal yang baik melekat kepada pribadi yang disebut sebagai mukmin. Oleh karena itu, seruan Tuhan Yang Maha Esa untuk melakukan hal kebaikan selalu tertuju kepada mukmin, baik dalam bentuk mufrad maupun jamak dan lawan kata dari mukmin itu adalah kafir.

\section{B. Wujud Mukmin dalam Setiap Diri Peserta Didik}

Peserta didik adalah sasaran utama dalam dunia pendidikan, ${ }^{119}$ yang mempunyai tujuan agar mereka nantinya mempunyai prilaku yang berakhlakul

${ }_{117}$ Mevi Linawati, http//m.liputan6.com/news/read/3250888/, diakses pada 4 Juni 2018.

118 Syafruddin Nurdin, dan Adrianto, Kurikulum dan Pembelajaran, (Jakarta: PT. Rajagrafindo Persada, 2016), hlm. 67-68.

${ }^{119}$ Ibid., hlm. 9-10. 
karimah, ${ }^{120}$ mengatasi kebodohan dan meningkatkan daya pengetahuan, sehingga dengan semakin tinggi kualitas pendidikan yang diterima oleh para peserta didik, maka semakin mudah dalam membangun bangsa dan negara, sasaran itulah yang menjadi cita-cita utama dalam dunia pedidikan. ${ }^{121}$

Pembangunan karakter peserta didik yang menjadi ciri khas dalam dunia pendidikan yang dimuat dalam kurikulum 2013, menjadi acuan pendidikan Indonesia sekarang dan sedang digalakkan untuk dimanifestasikan dalam krangka yang nyata. Begitu juga dengan pendidikan agama yang manjadi muatan salah satu bahan ajar dalam kurikulum 2013, yang dikenal dengan Kompetensi Inti, di mana di sana pada Kompetensi Inti I menyampaikan "Menghayati dan mengamalkan ajaran agama yang dianutnya. ${ }^{122}$ Pendidikan agama yang salah satunya adalah pendidikan agama Islam memberikan konstribusi yang besar dalam pembentukan karakter pada peserta didik.

Namun, beberapa muatan pelajaran yang disajikan, pendidikan agama belum banyak menyentuh aspek batin yang menjadi 'central pokok' bagi pembentukan karakter. Indokator utama masih terpusat kepada bagaimana peserta didik ditekankan untuk mengamalkan ajaran agama, tanpa pernah diajak untuk mengetahui ushul atau dasar berpijak kenapa agama memerintahkan agar supaya anak didik harus mengamalkan kebaikan? Sebab itulah, penulis dalam hal ini mengistilahkan "central pokok" yang mendasar pada setiap diri manusia dengan sebutan "mukmin".

Mukmin bukanlah agama dan kepercayaan, tetapi mukmin yang dimaksud oleh penulis adalah sebagaimana disebut dalam Hadits Qudsi, "Hambaku di dalam hati namanya mukmin". 123 Di dalam setiap hati manusia termasuk juga para peserta didik terdapat rasa yang selalu berkata jujur (siddiq). Kenapa dia selalu jujur? Karena dia kepercayaan Tuhannya (amanah). Dia selalu menyampai apa yang dia rasakan (tabligh). Dia cerdas (fathonah), yaitu bisa membedakan apa yang diarasakan apakah

${ }_{120}$ Abdullah Idi, Pengembangan Kurikulum Teori dan Praktik, (Jakarta: PT. RajaGrafindo Persada, 2016), hlm. 41-42.

121 Teguh Triwiyanto, Pengantar Pendidikan, (Jakarta: Bumi Aksara, 2014), hlm. 16.

122 Lampiran 2. Menteri Pendidikan dan Kebudayaan Republik Indonesia. Peraturan Menteri Pendidikan dan Kebudayaan Indonesia Nomor 70 Tahun 2013, hlm. 9-10.

123 Syarif, Wujud di Balik Teks, Studi al-Qur'an dengan Pendekatan Hikmah, (Bandung: Nusa Media, 2014), hlm. 31. 
dia sedang bahagia atau sedih? Apakah dia sedang baik atau sedang jahat? Itulah sifat yang melakat pada mukmin yaitu, sifat siddiq, amanah, tabligh, dan fathonah. Sebab, di dalam kitab suci al-Qur'an, Allah SWT mengajak untuk melakukan hal kabaikan, maka yang diseru adalah mukmin. Untuk melihat seperti apa ungkapan mukmin yang disampaikan oleh Allah SWT di dalam kitab al-Qur'an bisa dilihat dalam beberapa ayat berikut ini:

1. Surah al-Anfal ayat 2:

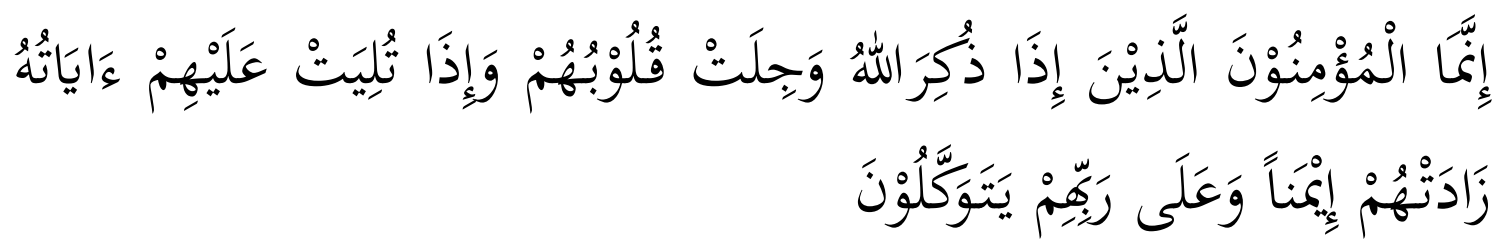

Artinya: "Sesungguhnya orang-orang mukmin ialah mereka yang bila diingat Allah gemetarlah hati mereka, dan apabila dibacakan ayat-ayat-Nya bertambahlah iman mereka (karenanya), dan hanya kepada Tuhanlah mereka bertawakkal". (QS. al-Anfal: 12)..$^{124}$

2. Surah an-Nisa' ayat 146:

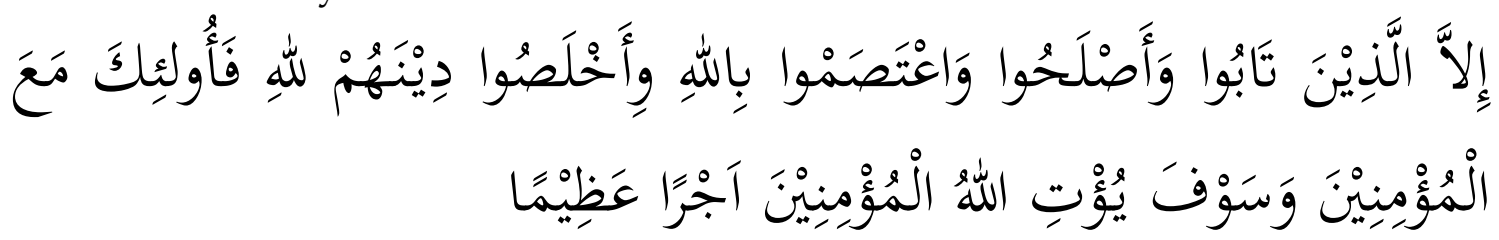

Artinya: "Kecuali orang-orang yang taubat dan mengadakan perbaikan dan berpegang teguh dengan (agama) Allah dan tulus ikhlas (mengerjakan) agama mereka karena Allah. Maka mereka itu adalah bersama-sama orang-orang yang mukmin dan kelak Allah akan memberikan kepada orang-orang mukmin pahala yang besar". (QS. AnNisa': 146) ${ }^{125}$

3. Surah al-Anfal ayat 3-4:

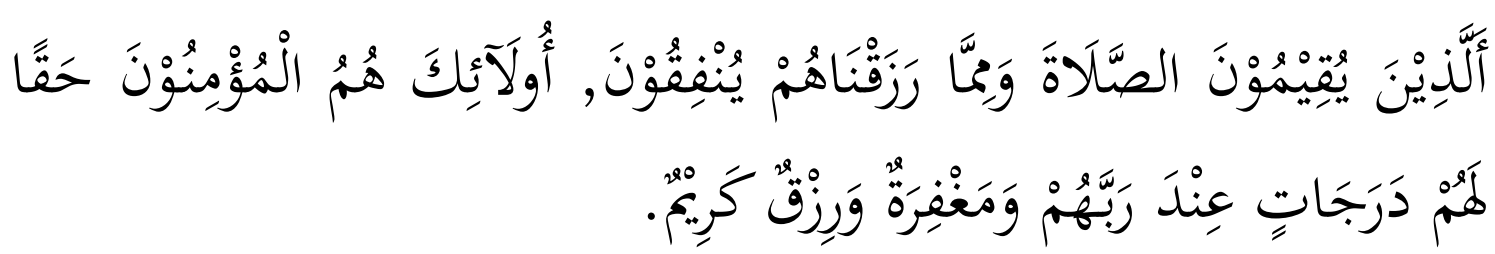

Artinya: "(Yaitu) orang-orang yang mendirikan shalat dan yang menafkahkan sebagian dari rezki yang Kami berikan kepada mereka. Itulah orang-orang-orang

124 Departemen Agama, Al-Qur'an dan Terjemahannya, (Semarang: PT. Kusmudasmoro Grafindo, 1994), hlm. 260.

125 Ibid., hlm. 147. 
mukmin yang sebenarnya. mereka akan memperoleh beberapa derajat ketinggian di sisi Tuhannya dan ampunan serta rezki (nikmat) yang mulia". (QS. Al-Anfal: 3-4)126

4. Surah al-Anfal 74:

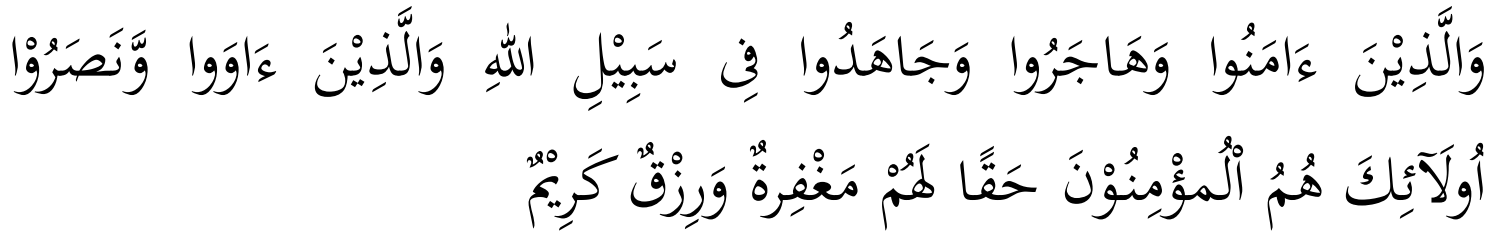

Artinya: "Dan orang-orang mukmin dan berhijrah dan berjihad pada jalan Allah, dan orang-orang yang memberi tempat kediaman dan memberi pertolongan (kepada orangorang muhajirin), mereka Itulah orang-orang yang sebenar-benarnya mukmin. mereka memperoleh ampunan dan rezki (nikmat) yang mulia". (QS. Al-Anfal:74) ${ }^{127}$

5. Surah at-Taubah ayat 26 :

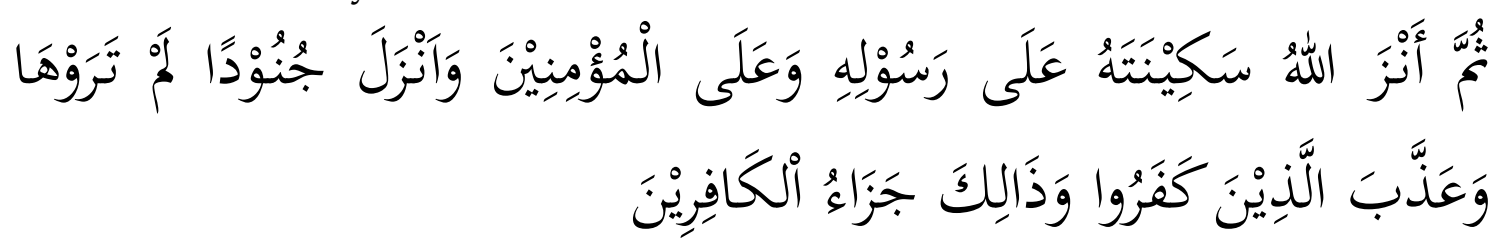

Artinya: "Kemudian Allah menurunkan ketenangan kepada RasulNya dan kepada orang-orang mukmin, dan Allah menurunkan bala tentara yang kamu tiada melihatnya, dan Allah menimpakan bencana kepada orang- orang yang kafir, dan demikianlah pembalasan kepada orang-orang yang kafir". (QS. At-Taubah: 26) ${ }^{128}$

6. Sura al-Hujarat ayat 10 :

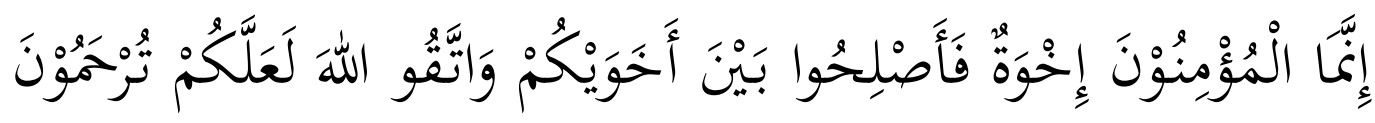

Artinya: "Sesungguhnya orang-orang mukmin itu bersaudara. sebab itu damaikanlah (perbaikilah hubungan) antara kedua saudaramu itu dan takutlah terhadap Allah, supaya kamu mendapat rahmat". (QS. Al-Hujarat: 10)129

7. Surah at-Taubah ayat 112:

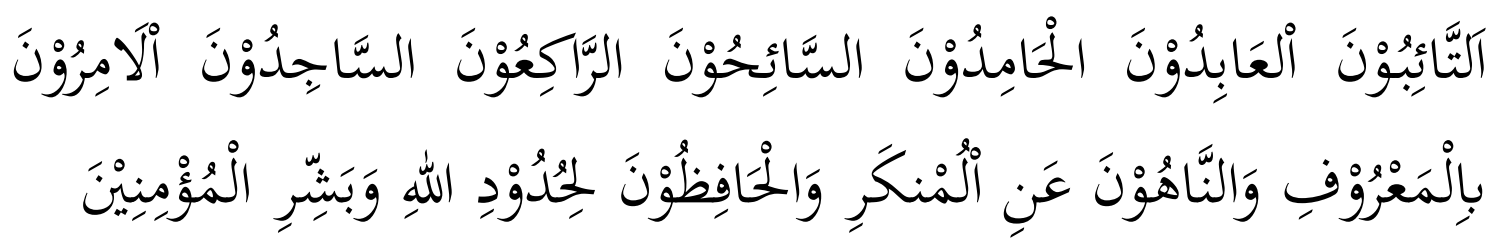

Artinya: "Mereka itu adalah orang-orang yang bertaubat, yang beribadat, yang memuji, yang melawat yang ruku', yang sujud, yang menyuruh berbuat ma'ruf dan

126 Ibid., hlm. 260.

127 Ibid., hlm. 273.

128 Ibid., hlm. 281-282.

${ }^{129}$ Ibid., hlm. 846. 
mencegah berbuat Munkar dan yang memelihara hukum-hukum Allah. dan gembirakanlah orang-orang mukmin itu". (QS. At-Taubah: 112)

Tidak kurang dari 104 firman Allah di dalam kitab al-Qur'an, baik dalam bentuk kata mufrad maupun jamak yang menyatakan tentang prilaku orang-orang mukmin, artinya prilaku orang yang mengikut hati nuraninya. Persoalan yang mendasar ialah, bagaimana bertemu dan mengetahui di mana mukmin itu berada? Karena tidak semua pribadi itu bisa mencerminkan prilaku mukmin sebagaimana yang disampaikan Tuhan melalui firmannya di dalam kitab al-Qur'an.

Hadits Qudsi menerangkan bahwa mukmin itu ada di dalam setiap hati manusia:

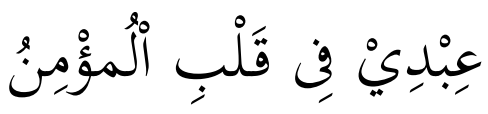

Artinya: "Hambaku di dalam hati namanya mukmin".

Kata lain mukmin itu disebut oleh para ahli sufi sebagai "Nurani" yang berarti 'cahayaku.' ${ }^{131}$ Oleh karena itu, dalam setiap hati manusia itu ada nurani yang disebut bahwa dia selalu benar, jujur, tidak pernah berbohong, karena mukmin (nurani) itu adalah amanah (kepercayaan) Allah. Hati nurani itu selalu menyampaikan bahwa yang baik itu baik, yang jahat itu jahat, karena dia fathonah (cerdas), bisa membedakan yang haq dan yang bathil.

Dunia pendidikan sekarang melupakan hal yang sangat mendasar, yaitu hati nurani (mukmin). Bahkan pendidikan agama sekalipun sudah tidak menyentuh hal yang sangat fundamental tersebut. Sedangkan firman Tuhan yang disampaikan pertama kali oleh Nabi Muhammad SAW dalam surah al-'Alaq ayat 1-5 tentang "Membaca dengan nama Tuhan yang telah menjadikan manusia dari segumpal darah". ${ }^{132}$ Artinya, manusia sebagai objek pendidikan patut untuk dikaji, agar supaya bisa diketahui kenapa manusia mempunyai karakter baik dan buruk?

Allah SWT dalam surah al-Thoriq ayat 5:

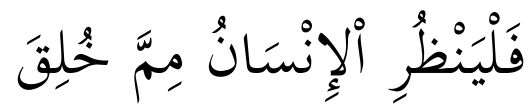

130 Ibid., hlm. 299-300.

${ }^{131}$ Ibn 'Atha' illah al-Sakandari, Pencerah Kalbu Wacana Moral dan Spritual. (Jakarta: PT. Serambi Ilmu Semesta, 2002), hlm. 118.

${ }^{132}$ Departemen Agama, Al-Qur'an dan Terjemahannya, hlm. 1079. 
Artinya: "Hendaklah manusia memikiran dari apa asal kejadiannya". (QS. At-Thoriq: 5)

Apa sebabnya manusia harus memikirkan asal kejadiannya? Hal tersebut disebabkan firman yang lain menyatakan bahwa, di dalam setiap manusia diilhamkan kebaikan dan keburukan. Hal ini sebagaimana firman Allah dalam surah as-Syams ayat 8:133

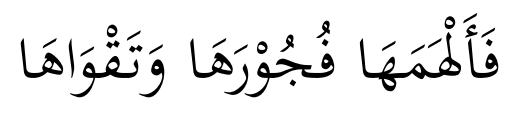

Artinya: "Maka Allah mengilhamkan kepada jiwa itu (jalan) kefasikan dan ketakwaannya". (QS. As-Syams: 8)

Selanjutnya, dari mana munculnya kebaikan dan keburukan? Sehingga terkadang manusia dengan mudahnya menjelakkan saudaranya, dengan mudahnya melanggar aturan, dengan mudahnya manusia saling menghujat, memfitnah bahkan saling membunuh. Hal ini berakibat terjadi pertentangan yang tidak pernah selasai di dalam diri setiap manusia, yaitu seruan untuk melakukan kebaikan dan rayuan untuk melakukan kejahatan dan kemaksiatan. Untuk itulah perlu disimak dan dikaji lebih mendalam firman Allah dalam surah as-Syasm ayat 8 itu. Maka dari itu, perlu diketahui dari mana munculnya sifat jahat yang menyebabkan manusia tidak bisa menampilkan karakter mukmin.

\section{Sifat Jahat (Fujur) dalam Setiap Diri Manusia}

Ketika Nabi Muhammad SAW, baru pulang dari perang badar, Nabi bersabda:

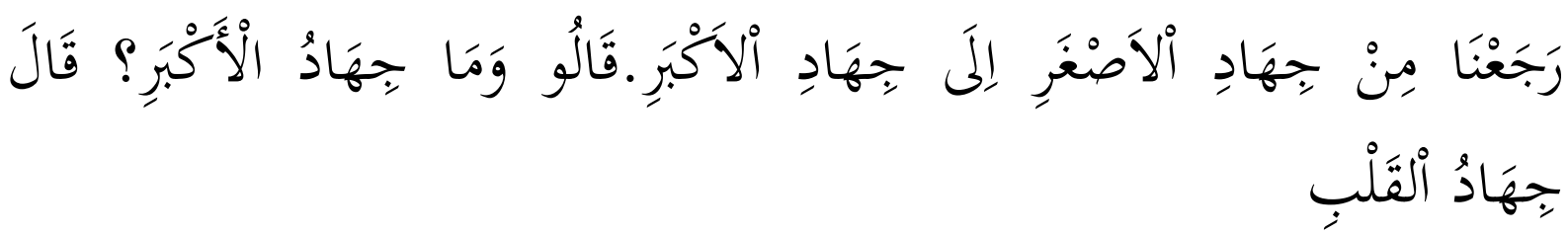

Artinya: "Kami baru pulang dari perang kecil manuju perang besar." Para sahabat bertanya: "Apakah perang besar itu?" Nabi bersabda: "Itulah perang hati melawan hawa nafsunya". ${ }^{134}$

Dalam Hadits yang lain menyatakan:

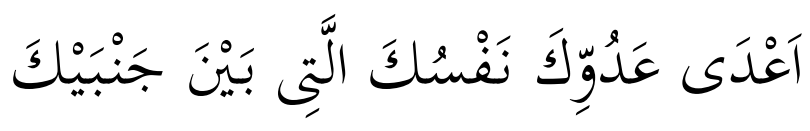

133 Ibid., hlm. 1064.

134 Imam ibnu al-Baz, Majmuk Fatawi vol 26. (Bairut: Darul Hikmah. t.t), hlm. 381. 
Artinya: "Nyata musuh yang mesti kamu perangi ada diantara dua lambungmu".135

Ada apa di dalam diri, sehingga Nabi bersabda bahwa musuh itu ada pada diri sendiri? Sebab itulah perlu kiranya diketahui asal usul kejadian manusia. Hadits Nabi juga menyatakan tentang asal kejadian manusia:

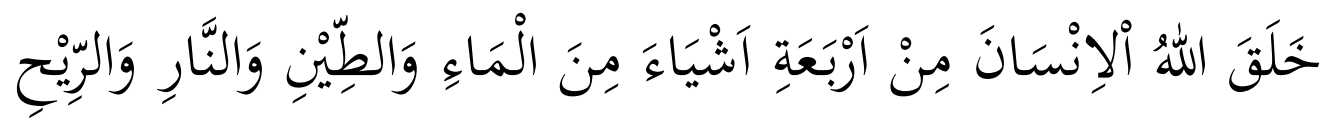

Artinya: "Allah menciptakan manusia itu dari empat sesuatu, dari air, tanah, api dan angin". 136

Ada apa dengan angin, air, tanah dan api? Ternyata ada rahasia atau ruh. Setiap sesuatu yang hidup itu pasti karena ada ruhnya, tubuh manusia itu dijadikan oleh Allah dari ruh angin, air, tanah dan api, sebab itulah manusia karena bersama sifat jelek yang melekat pada ruh angin, air , tanah dan api sehingga manusia tidak bisa memunculkan karakter mukminnya. Untuk melihat lebih jelas, coba perhatikan bagaimana kinerja dari empat ruh tersebut.

Bagaimana kinerja dari ruh angin, air, tanah dan api? Maka butuh diketahui dari mana munculnya hawa, nafsu, dunia, syetan yang selalu membuat manusai berselisih? Pertama, kenapa ada hawa? Karena rahasia angin (ruh angin/ruh raihan) telah memenuhi segala rongga tubuh manusia, hawa sifatnya pantang kelintasan atautidak mau didahului. ${ }^{137}$ Pintunya adalah telinga. Telinga tidak bisa mendengar sesuatu yang lebih dari pada dirinya, manusia tiba-tiba muncul sifat sakwa-sangka, hatinya menjadi tidak enak, rasanya terganggu. Sifat itu muncul disebabkan karena ruh angin berbisik ketika telinga mendengar susuatu yang lebih daripada dirinya.

Kedua, kenapa ada nafsu? Karena rahasia air (ruh air namanya ruh rahmani) telah menjadi urat, benak dan tulang, adalah nafsu sifatnya pantang kerendahan ${ }^{138}$ (tidak mau direndahkan) pintu nafsu itu mata. Mata ketika melihat sesuatu yang lebih baik, langsung rasa di dalam hati menjadi 'jatuh' maka muncullah istilah jatuh cinta, sehingga prilaku nafsu ini membuat manusia menjadi mudah jatuh cinta kepada apa saja yang 'lebih' menurut pandangan matanya. Selain itu sifat nafsu itu

${ }^{135}$ Imam al-Ghozali, Ihya' Ulum al-Din, Vol. II, (Bairut: Katib al-Syu'ab, t.t), hlm. 1345.

136 Jala al-Din abdul-Rahman bin Abu Bakar al-Suyuti, Arrahman fi al-Tibbi wa al-Hikmah, (Bairut: Darul Kasyfil Amaliyah, 1971), hlm. 5.

137 Syarif, Wujud di balik......, hlm. 177.

138 Ibid. 
pantang kerendahan (tidak mau direndahkan), sehingga menyebabkan manusia terkadang selalu ingin dipandang tinggi, ketika direndahkan, manusia tidak bisa menerimanya, bahkan terkadang dengan berbagai macam cara, supaya jabatan yang dianggap tinggi itu dipertahankan, sampai terkadang "harga dirinya-pun" ditaruhkan demi tidak direndahkan oleh orang lain.

Ketiga, kenapa ada dunia? Karena rahasia tanah (ruh tanah yang bernama ruh jasmani) telah menjadi daging, kulit, bulu atau roma pada setiap tubuh manusia, 139 dunia sifatnya pantang kekurangan, pintu dunia itu adalah mulut. Dengan kepiawaian mulut dan lidahnya, manusia berupaya mencukupi kesenangan dunianya. Dengan adanya sifat pantang kekurangan, manusia tidak pernah ingin kurang, maka manusia terkadang harus menimbun kesenangan dunia, berupa makanan, minuman, emas dan hal-hal kesenangan dunia lainnya hingga berlebih. Manusia sangat susah untuk berbagi, bahkan sifat pantang kekurangan inilah menyebabkan banyak dari oknum petinggi negeri ini, harus berurusan dengan pihak berwajib, seperti kepolisian, kejaksaan dan KPK, disebabkan sifat pantang kekurangan menyebabkan manusia tamak dan serakah, kemudian ditutupinya sifat serakah dan tamak itu dengan selalu berkata dusta.

Keempat, kenapa ada syetan? Karena rahasia api telah menjadi darah pada tubuh manusia, rahasia api (ruh api namanya ruh idhofi) mempunyai sifat pantang kalah. ${ }^{140}$ Sifat pantang kalah inilah yang diikuti oleh sifat pantang kelintasan, kerendahan dan kekurangan, sehingga menyebabkan karakter mukmin tertutup (kufur). Makakarena itu, kafir sesungguhnya bukanlah agama, kafir sesungguhnya adalah pelaku atau subjek ketika manusia mengikuti sifat pantang kelintasan, kerendahan, kekurangan dan pantang kalah, sehingga karakter mukmin yang jujur, amanah, tabligh dan fathonah tertutup atau terhijab dan perbuatan yang menghijab karakter mukmin itu disebut perbuatan kafir.

Empat rahasia inilah yang belum diketahui oleh kebanyakan manusia, begitu juga di dalam dunia pendidikan. Dua karekter yang saling bertentangan di dalam setiap diri manusia itu, kurang mendapat sentuhan dalam pembelajaran, 
dikarenakan manusia tidak mau melihat, meneliti tentang sebab dasar manusia berselisih, sebab itulah untuk bisa memisah antara makmin dan kafir, manusia butuh agama, sehingga agama tidak bisa lepas dari dunia pendidikan. Kalau hadits Nabi Muhammad SAW. menyebutkan dalam sabdanya:

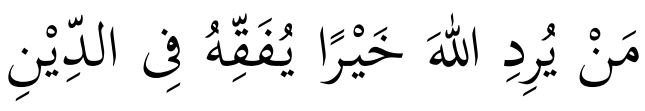

Artinya: "Barang siapa yang dikehendaki dalam kebaikan, maka orang tersebut diberikan kepahaman dalam urusan agama". ${ }^{141}$

Kebaikan dan agama diibaratkan seperti dua sisi mata uang yang tidak bisa dipisahkan, maka ketika karakter mukmin tidak muncul dan bahkan hilang dalam pribadi manusia, disebabkan agama tidak berdiri tegak pada pribadi anak bangsa, maka yang terjadi karakter mukmin tidak tampak dalam prilaku kehidupan nyata.

\section{Peran Ilmu Ushul, Fiqih dan Tasawwuf dalam Pembentukan Karekter Mukmin}

Sebagaimana yang disebutkan di atas bahwa, mukmin itu ada di dalam setiap hati manusia. Dia yang disebut nurani dan sekarang mukmin itu ada di dalam "tubuh sebatang" yang dijadikan oleh Allah dari segumpal darah yang berasal dari setetes air hina. Sebagaimana firman Allah dalam surah as-Sajadah ayat 8:

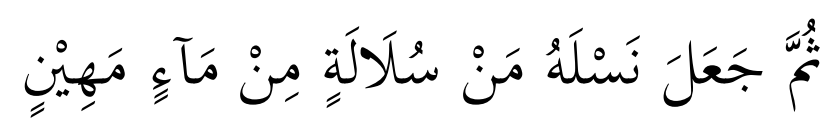

Artinya: "Kemudian Dia menjadikan keturunannya dari saripati air yang hina". (QS. AsSajadah: 8$)^{142}$

Kehinaan itu disebabkan karena pada setetes sperma dan ovum di dalamnya terdapat rahasia angin, air, tanah, dan api (ruh raihan, ruh rahmani, ruh jasmani dan ruh idhofi) yang disempurnakan oleh Allah dengan ditiupkan ruh mukmin ke dalamnya sebagaimana firman Allah dalam surah as-Sajadah ayat 9:

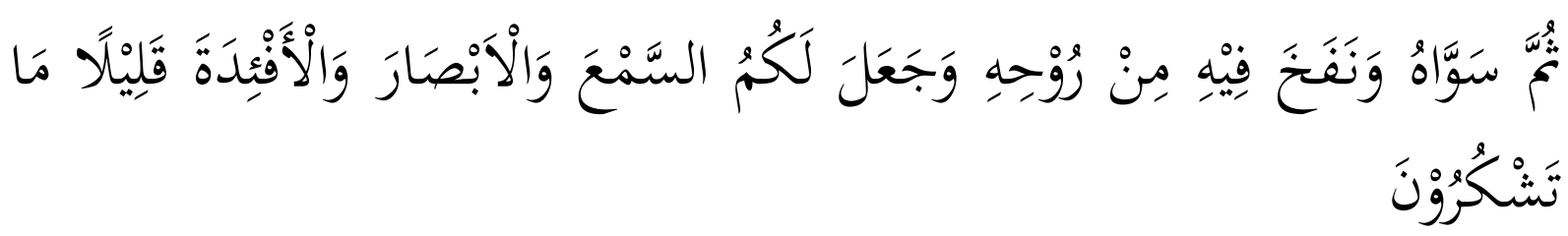

${ }^{141}$ Jalal al-Din al-Suyuti, al-Jami' al-Shaghir fi ahadits al-Basyir al-Nadhir, Juz II, (Bandung: Syirkah al-Maarif, t.t), hlm. 183.

142 Depertemen Agama, al-Qur'an......, hlm. 661. 
Artinya: "Kemudian Dia menyempurnakan dan meniupkan ke dalamnya ruh (ciptaan)-Nya dan Dia menjadikan bagi kamu pendengaran, penglihatan dan hati; (tetapi) kamu sedikit sekali bersyukur". (QS. As-Sajadah: 9) ${ }^{143}$

Dengan ditiupkannya ruh ke dalam jasad, maka setetes air hina itu menjadi tubuh yang indah. Tubuh manusia berasal dari tanah, sedangkan ruh (jiwa) berasal dari sari substansi immateri di alam ghaib. ${ }^{144}$ Tubuh manusia membawa sifat kejelekan, sedangkan nurani membawa sifat kebaikan. Dua sifat itu sekarang sedang menyatu dalam diri manusia, sehingga Nabi Muhammad SAW menyatakan: "Musuh yang mesti diperangi ada pada tubuhmu". Oleh karena itu, perlu untuk dijelaskan asalusul tentang kejadian manusia itu, agar fiqih yang menjadi amalan nyata setiap hari, tidak hanya menjadi amalan rutin yang tidak mempunyai makna.

Lalu, bagaimana cara supaya karakter mukmin tampak dalam kehidupan anak didik? Caranya ialah ketiga pilar ilmu tidak bisa dipisahkan. Tiga pilar ilmu agama yakni ilmu ushul, fiqih, dan tasawwuf harus duduk dan menjadi ciri bagi anak bangsa. Dengan definisi yang sederhana dan mudah untuk dipahami bahwa: "Ilmu ushul adalah ilmu yang menjelaskan asal kajadian dari segala sesuatu, 145 ilmu fiqih adalah ilmu yang membahas tentang amalan nyata, ${ }^{146}$ dan ilmu tasawwuf adalah ilmu yang tidak bisa lagi dibantah oleh hukum akal".

Sebagaimana contoh sederhana, kenapa seorang laki-laki yang menyentuh seorang perempuan yang bukan muhrimnya mesti berwudhu' ketika hendak malakukan sholat? Sedangkan yang menyentuh tangannya, kenapa yang dibasuh mesti muka, kedua tangan, sebagian kepala, sunnah telinga dan wajib membasuh kedua kaki? Kalau tidak diketahui ushulnya, maka amalan yang diajarkan fiqih menjadi ambigu. Kenapa mesti bersuci ketika hendak menyembah kepada Allah SWT? Maka akal akan terus bertanya. Sebab itulah, mesti harus dijelaskan ushulnya supaya ilmu fiqih menjadi amalan yang nyata.

143 Ibid.

${ }^{144}$ Muhammad Ilham Shaleh, "Filsafat Jiwa dalam Al-Qur'an," dalam Jurnal Adabiyah, Vol. XIV, No. 1, 2014, hlm. 33.

145 Firdaus, Ushul Fiqh Metode Mengkaji dan Memahami Hukum Islam secara Komprehensif, (Depok: PT. RajaGrafindo Persada, 2017), hlm. 1.

146 Ma'shum Zein, Menguasai Ilmu Ushul Fiqih Apa dan Bagaimana Hukum Islam Berdasrikan dari Sumber-Sumbernya, (Yogyakarta: Pustaka Pesantren, 2013), hlm. 28. 
Ilmu ushul, fiqih dan tasawwuf adalah ilmu yang terintegrasi dan tidak bisa berdiri sendiri, lalu bagaimana tiga ilmu itu bisa membuat karakter peserta didik sesuai dengan nilai agama. Sebagai contohnya, mukmin itu berasal dari Allah SWT. tentu dahulunya dia sebelum ditiupkan ke dalam tubuh manusia adalah suci, karena dia berasal dari Yang Maha Suci. Sebagaimana sabda Nabi Muhammad SAW:

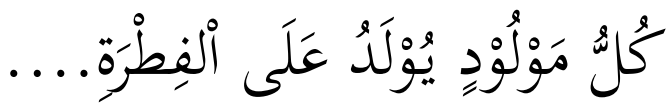

Artinya: "Setiap yang dilahirkan dalam keadaan suci..."147

Ruh ketika lahir masih suci, belum terkontaminasi oleh sifat hawa, nafsu, dunia dan syetan, tetapi ketika tubuhnya sudah 'aqil baligh dan termasuk dalam kategore ahliyyah ${ }^{148}$ dalam subyek hukum, maka ruh yang ditiupkan dari Tuhan itu yang bernama mukmin mulai terkontaminasi oleh hawa-nafsu-dunia-syetan. Sebagai contoh, dulunya seorang anak laki-laki sebelum berusia tujuh tahun ketika menyentuh seorang perempuan yang bukan muhrimnya biasa aja. Tetapi, ketika aqil-baligh ketika bersentuhan dengan yang bukan muhrimnya, hatinya merasakan sesuatu yang berbeda. Apabila tersentuh nafsunya, maka dia telah mengotori amanah Allah yang dulu ketika lahir dalam keadaan suci. Dampaknya, ketika dia ingin menghadap kepada Allah SWT, dia mesti kembali dalam keadaan suci, maka fiqih mengaturnya dengan tata cara berwudhu' yang benar.

Kenapa yang dibasuh adalah wajah, kedua tangan, sebagaian kepala, sunnah membasuh telinga dan wajib membasuh kaki? Karena hamba Allah yang sedang lupa akan dirinya, bermaksiat kepada Allah sehingga ia menjadi kotor, maka yang dibasuh sesungguhnya adalah yang punya muka, tangan, kepala, telinga dan kaki. Sehingga tujuh anggota itu harus dibasuhnya dalam wudhu'. Kalaupun tidak ada air, maka fiqih membolehkan untuk bertayammum dan alat yang dipakai adalah debu, karena yang kotor bukanlah fisik, tetapi dia telah mengotori amanah Allah

147 Imam Malik, al-Muwatha', Juz I, (Bairut: Maktabah al-Busro, t.t), hlm. 241.

${ }^{148}$ Ahliyyah adalah kelayakan seseorang dalam menerima hak dan melakukan kewajiban. Dalam hal ini ialah termasuk kepada alahliyah $a l-i^{\prime} d a^{\prime}$, yaitu kelayakan untuk melakukan perbuatan hukum yang melakukan hak dan kewajiban. Lihat: M. Lutfi Hakim, "Keadilan Kewarisan Islam terhadap Bagian Waris 2:1 antara Laki-Laki dengan Perempuan Perspektif Filsafat Hukum Islam," dalam Jurnal Al-Maslahah, Vol. 12, No. 1, April 2016, hlm. 14. 
yang suci yang ditiupkan oleh Allah dimana dulu sebelum terpari ke dalam tubuh membawa sifat kebaikan (suci).

Ajaran Agama yang konprehensif seperti contoh di atas, yang mesti diajarkan dalam materi pembelajaran agama, karena yang terpenting adalah bagaimana membersihkan diri yang datang dari Allah SWT? Ilmu tasawwuf memberi tahukan ketika berwudhu' untuk bermohon kepada Allah agar supaya diampuni akan dosadosa yang telah ia lakukan, sehingga selasai berwudhu', kita dianjurkan untuk berdo'a kepada Allah agar supaya dijadikan sebagai hamba Allah yang bertaubat, bersuci dan menjadi hamba Allah yang sholeh.

Inilah contoh ketika tahu usulnya, kemudian mengamalkan amalan yang nyata (fiqih), barulah apa yang diamalkannya itu masuk akal baginya itulah yang disebut tasawwuf, artinya apa yang dikerjakan tidak bisa lagi dibantah oleh hukum akal, ketika itu yang terjadi pada setiap anak didik, baru sempurnalah dia memahami agama, sehingga sesuai dengan sabda Nabi Muhammad SAW.

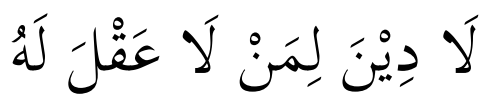

Artinya: "Tidak ada agama yang tidak masuk akal".149

Sebab itulah, karakter mukmin mesti dididik dengan agama, tidak bisa dengan pengetahuan murni. Hal itu dikarenakan, manusia diciptakan oleh Tuhan, tentu Tuhan jualah yang tahu cara memperbaiki manusia. Agar karakter anak bangsa bisa santun, penyayang, saling menghargai, maka ajaran agama berlandaskan tiga pilar ilmu ushul, fiqih, dan tasawwuf mesti harus hadir dalam setiap pembelajaran.

Kurikulum 2013 memberikan pesan yang kuat agar pendidikan karakter tumbuh dan menjadi ciri khas dari pendidikan Indonesia. Di mana sudah dikenal dari filosifi bangsa Indonesia yang tertuang dalam Pancasila dan UUD 1945, bahwa Bangsa Indonesia adalah bangsa yang agamis yang menjunjung tinggi nilai-nilai kejujuran, keadilan, persatuan dan hal-hal yang positif sebagai budi pekerti anak bangsa. Hal ini telah disampaikan oleh Pendiri Bangsa Indonesia, Soekarno: "Bahwa bangsa Indonesia mesti mempunyai karakter dan karakter itu akan terbentuk apabila bangsa

${ }^{149}$ Al-Suyuthi, Zail al-Lala'i Masnu'ah, (Riyad: Maktabah al-Ma'arif, t.t), hlm. 66. 
Indonesai terbebas dari penjajahan, maka dalam mengisi kemerdekaan Indonesia, karakter anak bangsa mesti nyata dalam pribadinya, yaitu mempunyai nilai ketuhanan, keadilan, persatuan, kerakyatan dalam kehidupan sosial yang baik". ${ }^{150}$

\section{E. Kesimpulan}

Dari pembahasan di atas, dapat disimpulkan bahwa manusia itu mempunyai dua sisi yang saling bertentang yaitu dua sifat: pertama sifat jelak dan kedua sifat baik. Sifat jelak berasal dari sifat bawaan tubuh yang dijadikan oleh Allah dari empat rahasia/ruh yaitu ruh angin, ruh air, ruh tanah dan ruh api, yang membawa sifat pantang kelintasan (hawa), sifat pantang kerendahan (nafsu), sifat pentang kekurangan (dunia) dan sifat pantang kalah (syetan), yang ada pada setetes air yang hina (sperma dan ovum). Sedangkan sifat baik itu adalah sifat bawaan ruh yang ditiupkan oleh Allah yang disebut mukmin dan dia sekarang ada di dalam setiap hati manusia yang disebut dengan hati nurani.

Ilmu agama tidak bisa dihilangkan, agar karakter mukmin itu muncul dan menjadi karakter bagi peserta didik, dengan memberi tahu ilmu ushul yaitu bahwa segala sesuatu pasti ada asalnya, sehingga ritual amalan menjadi nyata dalam dirinya, kepahaman itu yang disebut sebagai ilmu fiqih dan tidak menjadi pengetahuan yang ambigu, sehingga apapun yang diamalkan oleh peserta didik akan masuk pada akalnya dan itulah yang disebut sebagai ilmu tasawwuf. Tiga pilar ilmu itu mesti harus berintegrasi supaya bisa memberitahukan kepada peserta didik, bahwa setiap manusia itu ada unsur baik dan unsur jahat, agar supaya unsur baik itu bisa menang, maka agama harus hadir dalam dunia pendidikan.

\section{DAFTAR PUSTAKA}

Ali, Sodiqin, Antropologi al-Qur'an, Model Dialektika Wahyu dan Budaya, Yogyakarta: ar-Ruzz Media Group, 2008.

Budiono, Santo, Karekter Menentukan Masa Depan Bangsa, Jakarta: PT. Gramedia, 2018.

${ }^{150}$ Doni Koesoema A, Pendidikan Karakter Strategi Mendidik Anak di Zaman Global, (Jakarta: PT Grasindo, 2018), hlm. 44. 
Departemen Agama, Al-Qur'an dan Terjemahannya, Semarang: PT. Kusmudasmoro Grafindo , 1994.

Firdaus, Ushul Figh Metode Mengkaji dan Memahami Hukum Islam secara Komprehensif, Depok: PT RajaGrafindo Persada, 2017.

Ghazali, Abu Hamid, Bidayatul Hidayah, Surabaya: Al-Maktabah, t.t.

Ghozali, Imam, Ihya' Ulum al-Din, Juz II, Bairut: Kitab al-Syu'ab, t.t.

Hakim, M. Lutfi, “Keadilan Kewarisan Islam terhadap Bagian Waris 2:1 antara LakiLaki dengan Perempuan Perspektif Filsafat Hukum Islam," dalam Jurnal AlMaslahah, Vol. 12, No. 1, April 2016. (DOI: https:// doi.org/10.24260/almaslahah.v12i1.339)

Idi, Abdullah, Pengembangan Kurikulum Teori dan Praktik, Jakarta: PT. RajaGrafindo Persada, 2016.

Inggried Dwi Wedhaswary, Nawacita Jokowi, https://nasional.kompos.com/read/2014/05/0754454/, diakses pada 20 Maret 2018.

Koesoema A, Doni, Pendidikan Karekter Strategi Mendidik Anak di Zaman Global, Jakarta: PT. Grasindo, 2018.

Lampiran 2, Menteri Pendidikan dan Kebudayaan Republik Indonesia. Peraturan Menteri Pendidikan dan Kebudayaan Indonesia Nomor 70 Tahun 2013.

Malik, Imam, al-Muwatha', Juz I, Bairut: Maktabah al-Busro, t.t.

Mevi Linawati, http/ m.liputan6.com/news/read/3250888/, diakses pada 4 juni 2018.

Nurdin, Syafruddin dan Adrianto, Kurikulum dan Pembelajaran, Jakarta: PT. Rajagrafindo Persada, 2016. 
Sakandari, Ibn 'Atha'illah, Pencerah Kalbu Wacana Moral dan Spritual, Jakarta: PT. Serambi Ilmu Semesta, 2002.

Shaleh, Muhammad Ilham, "Filsafat Jiwa dalam Al-Qur'an," dalam Jurnal Adabiyah, Vol. XIV, No. $\quad$ 1, 2014. (http://journal.uinalauddin.ac.id/index.php/adabiyah/article/view/357/pdf_16)

Suyuthi, Zail al-Lala'i Masnu'ah, Riyad: Maktabah al-Ma'arif, t.t.

Suyuti, Jala al-Din, bin Abu Bakar, Abdul-Rahman, Arrahman fi al-Tibbi wa al-Hikmah, Bairut: Darul Kasyfil Amaliyah, 1971.

Suyuti, Jalal al-Din. al-Jami' al-Shaghir fi ahadits al-Basyir al-Nadhir, Juz II, Bandung: Syirkah al-Maarif, t.t.

Syarif, Wujud di Balik Teks, Studi al-Qur'an dengan Pendekatan Hikmah, Bandung: Nusa Media, 2014.

Tirimidhi, bin Isa bin Sauri, Imam Abi Isa Muhammad, Sunan at-Tirmidhi, Juz I, Bairut: Muassah ar-Rahalah, t.t.

Triwiyanto, Teguh, Pengantar Pendidikan, Jakarta: Bumi Aksara, 2014.

Zein, Ma'shum, Menguasai ilmu Ushul Fiqih Apa dan Bagaimana Hukum Islam Berdasrikan dari Sumber-Sumbernya, Yogyakarta: Pustaka Pesantren, 2013. 